\title{
Squamous Cell Carcinoma under the Veil of a Trophic Ulcer in a Case of Hansen's Disease
}

\section{Safal Rahim}

\begin{abstract}
Hansen's disease is seldom associated with trophic ulcers, which over a period of time when neglected has the potential for malignant transformation. In this case report, a 44-year-old male patient previously treated for Hansen's disease presented with nonhealing plantar ulcer, who developed squamous cell carcinoma with metastasis in the lymph nodes. We highlight the importance of having a high degree of suspicion in each case as our patient was asymptomatic and repeated biopsies and lymph node Fine needle aspiration cytology (FNAC) were required to diagnosis.
\end{abstract}

Keywords: Hansen's disease, Leprosy, Marjolin's ulcer, Plantar ulcer, Squamous cell carcinoma, Trophic ulcer.

How to cite this article: Rahim S. Squamous Cell Carcinoma under the Veil of a Trophic Ulcer in a Case of Hansen's Disease. J Med Sci 2015;1(3):60-61.

Source of support: Nil

Conflict of interest: None

\section{INTRODUCTION}

Residual neurological deficit in Hansen's disease often results in chronic non-healing trophic ulcers. These ulcers when neglected or not properly managed have the predisposition for malignant transformation over a long period of time.

\section{CASE REPORT}

A 44-year-old male was referred to our outpatient clinic with a non-healing chronic plantar ulcer involving the right sole of the foot for duration of 2 years. He was diagnosed as multibacillary leprosy at the age of 15 years and had a history of regular treatment from the leprosy hospital. He had no past history of diabetes or hypertension and was not on any other medications.

Local examination revealed a large plantar ulcer involving almost the entire sole of the right foot, extending from the forefoot up to the heel, measuring $10 \times 6 \mathrm{~cm}$. The ulcer had everted hyperkeratotic edges in the

Postgraduate Student

Department of Dermatology, RajaRajeswari Medical College and Hospital, Bengaluru, Karnataka, India

Corresponding Author: Safal Rahim, Postgraduate Student Department of Dermatology, RajaRajeswari Medical College and Hospital, Bengaluru, Karnataka, India, e-mail: crl.rrmch@gmail.com lower lateral border with induration. The floor showed unhealthy granulation tissue with slough in areas with the fascia of the muscle visible. Sensory examination revealed glove and stocking examination. Peripheral nerve examination revealed bilateral ulnar and radial cutaneous nerve enlargement. On general examination, the patient had partial clawing of both hands with difficulty in walking. There was bilateral inguinal lymphadenopathy, the largest measuring $2 \times 2 \mathrm{~cm}$ on the right horizontal group, which was firm and non-tender.

Wedge biopsy done from the inferolateral quadrant of the ulcer showed cytomorphological changes, suggestive of micro invasive well-differentiated squamous cell carcinoma. Ultrasound-guided Fine needle aspiration cytology (FNAC) of the right inguinal lymph node revealed metastasis.

Other investigations included X-ray of the right foot, which showed multiple osteophytes in the 5th metatarsal with vascular calcifications. Ultrasonogram of abdomen and pelvis confirmed multiple bilateral lymph nodes, more on the right side. Chest $\mathrm{X}$-ray and routine blood investigations were unremarkable.

After due consultation with the Department of Plastic Surgery and Oncosurgery, the patient was taken up for wide local excision of the ulcer with a margin of $2 \mathrm{~cm}$ and right-sided inguinal lymph node dissection. Biopsies were done from the margins to ensure the complete excision of the tumor. The resultant defect was covered using split thickness graft harvested from the thigh. On subsequent follow-up, the patient showed good recovery with the graft being taken up well.

\section{DISCUSSION}

French surgeon Jean Nicholas Marjolin in 1828 coined the term “Ulcus Marjolini" or Marjolin's ulcer to describe chronic leg ulcers that showed warty changes. ${ }^{1}$ Later in 1903, Da Costa first used the term in describing tumors arising from chronic leg ulcers. ${ }^{2}$

Marjolin's ulcers reflect malignant degeneration arising within pre-existing scar tissue or chronic inflammatory skin lesions. ${ }^{3}$ Plantar aspect of foot in lower extremity is the common site for Marjolin's ulcers. ${ }^{4}$ They exhibit slow growth and are painless with a latent period between the primary pathology and malignant 
transformation. A maximum time lag to develop ulcers is 70 years. Nancarrow, Mcleod and Stauffer ${ }^{5-7}$ have reported in their case series a shortest time of 4 weeks.

Treves and Pack described two clinical types of Marjolin's ulcer: The flat indurated, infiltrative, ulcerative type and the less frequent, exophytic papillary form with the former having poorer prognosis. The malignant change often begins at the edge, which may show some warty change with elevation. Occasionally, there is the appearance of a mass within the scar or ulcer. The base of the ulcer becomes increasingly indurated with a granular, often necrotic floor with areas showing sloughing and discharge. Lymphatic spread may occur in the later stages when the tumor exceeds beyond the margins and regional lymph node metastasis is considered the most important prognostic factor. 8,9

The association between leprosy and malignant changes has been well documented in the literature. The reduced cell-mediated immunity in leprosy increases the risk for malignant changes. Cellular mutations are responsible for neoplastic transformations with infections serving as co-carcinogens. ${ }^{10}$

The mainstay for treatment for Marjolin's ulcer remains to be surgery. Wide local excision with a minimum margin of $2 \mathrm{~cm}$ of healthy tissue has been recommended by many authors. ${ }^{9,11}$ Recently, Moh's micrographic surgery has ensured complete local excision with safe margins.

Normally, the defects after resection are usually covered with a skin graft. If the underlying bed is not suitable, then a flap will be used ${ }^{12}$ for covering the defect. Amputations are indicated when deep invasion makes local excision difficult.

Regional metastases occur in 2 to $6 \%$ of cases; therefore, the regional nodes should be thoroughly assessed in a patient presenting with Marjolin's ulcer. In the presence of clinically palpable lymph nodes, dissection is generally advised. As per some of the investigators, it is considered as a prophylactic measure against regional node metastases. This is termed as prophylactic node dissections. ${ }^{9,13}$

\section{CONCLUSION}

We present this report because of the benign nature of the tumor with hardly any symptomatic discomfort to the patient or suspicion of malignancy. Repeated biopsies and FNACs were required to substantiate the evidence of the tumor and nodal metastases. Malignant changes in non-healing trophic ulcers of Hansen's disease may not be common, but can be missed if not vigilant. A high degree of suspicion and early specialist referral can be very vital as in our case.

\section{REFERENCES}

1. Treves N, Pack GT. The development of cancer in burn scars. Surg Gynecol Obstet 1930;51:749-782.

2. Cruickshank AH, Connel EM, Miller DG. Malignancy in scars, chronic ulcers and sinuses. J Clin Pathol 1963 Nov;16(6):573-580.

3. Sabin SR, Goldstein G, Rosenthal HG, Haynes KK. Aggressive squamous cell carcinoma originating as a Marjolin's ulcer. Dermatol Surg 2004 Feb;30(2 Pt 1):229-230.

4. Richardus JH, Smith TC. Squamous cell carcinoma in chronic ulcers in leprosy: a review of 38 consecutive cases. Lepr Rev 1991 Dec;62(4):381-388.

5. Nancarrow JD. Cicartrical cancer in South-West England: a regional plastic surgery unit's experience over a 20 year period. Br J Surg 1983:70(4):205-208.

6. McLeod JM. Burns and their treatment. London: Oxford University Press; 1918. p. 15.

7. Stauffer H. Malignant degeneration in Burns. California Med 1961 April;94:175-177.

8. Castillo J, Goldsmith HS. Burn scar carcinoma. Cancer J Clin 1968 May-Jun;18(3):140-142.

9. Novick M, Gard DA, Hardy SB, Spira M. Burn scar carcinoma: a review and analysis of 46 cases. J Trauma 1977 Oct;17(10):809-817.

10. Sandhya V, Anandan S, Nikilesh K, Narayan CD. Squamous cell carcinoma masquerading as a trophic ulcer in a patient with Hansen's disease. Int J Lower Extrem Wounds 2010 Dec;9(4):163-165.

11. Kowal-Vern A, Criswell BK. Burn scar neoplasms: a literature review and statistical analysis. Burns 2005 Jun;31(4):403-413.

12. Opara KO, Otene IC. Majorlin's ulcer: a review. Nigerian Health J 2011 Oct-Dec;11(4):107-111.

13. Hill BB, Sloan DA, Lee EY, McGrath PC, Kennady DE. Marjolin's ulcer of the foot caused by non-burn trauma. South Med J 1996 Jul;89(7):707-710. 